Article

\title{
Droplet Impact on the Cold Elastic Superhydrophobic Membrane with Low Ice Adhesion
}

\author{
Chenlu Qian, Qiang Li * and Xuemei Chen * \\ MIIT Key Laboratory of Thermal Control of Electronic Equipment, School of Energy and Power Engineering, \\ Nanjing University of Science and Technology, Nanjing 210094, China; qianchenlu359@163.com \\ * Correspondence: liqiang@njust.edu.cn (Q.L.); xuemeichen@njust.edu.cn (X.C.)
}

Received: 18 September 2020; Accepted: 5 October 2020; Published: 9 October 2020

\begin{abstract}
The elastic membranes with different surface stiffness were fabricated via spin-coating followed by the laser ablation. The as-fabricated elastic membrane exhibited superhydrophobicity with a rough microstructure. The droplet impacting experiment on the cold elastic superhydrophobic membrane was conducted, and the influence of surface stiffness and impacting speed on the droplet impacting process were investigated. It was found that the elastic superhydrophobic membrane exhibits a robust anti-icing performance compared with the elastic hydrophobic membrane. A lower surface stiffness corresponds to a larger deformation degree of the elastic membrane and to a smaller maximum droplet spreading diameter. Moreover, the contact time decreases with the increase of impacting speed as for the same stiffness of the cold elastic superhydrophobic membrane. The underlying mechanism of the cold elastic membrane with low ice adhesion may be due to the face that the deformation of the superhydrophobic membrane provides an elastic force for the droplet to detach from the surface and thus reduce the heat transfer between the droplet and the surface.
\end{abstract}

Keywords: droplet impact; cold elastic membrane; superhydrophobic; ice adhesion; anti-icing

\section{Introduction}

Ice accumulation is a common and serious phenomenon that exists in numerous industrial fields such as electricity transportation, wind turbine and air conditioning [1-3]. The ice accretion may cause the failure of conductors, decrease the efficiency of air conditioning and even cause the system shutdown, which would pose a huge energy consumption and potential safety hazard $[4,5]$. Therefore, developing an effective and reliable method to reduce ice accumulation is of great practical importance.

There are mainly two methods to mitigate the ice accretion on cold surfaces: (1) remove ice through external stimulation such as electric field, thermal source and ultrasonic vibrations [6-8]; (2) suppress ice formation by delaying the ice nucleation [9-11]. The traditional methods to remove ice through external stimulation increase energy consumption and are inefficient. Reducing ice adhesion of the droplet to the surface is considered as the most effective way to alleviate ice accumulation because it does not require of any external energy [12-14]. Therefore, numerous investigations have been carried out to develop surfaces with anti-icing properties to reduce ice adhesion. Foremost among these studies is the use of slippery liquid-infused porous surfaces (SLIPS) [15-17], which is created by infiltrating the micro/nanostructured porous structures with a lubricating fluid. The lubricant on the SLIPS is immiscible to most aqueous solutions and effectively blocks the direct contact between droplet and surface. Therefore, the SLIPS possess a low contact angle hysteresis and can achieve low ice adhesion. In addition, SLIPS also exhibit self-healing property, as the surface morphology can be recovered after mechanical damage. However, the SLIPS have limited effectiveness once the lubricant film losses its stability. When the lubricating film is depleted, the SLIPS would lose anti-icing property $[18,19]$. Therefore, the SLIPS may not be durable for practical applications. 
Another research line to reduce ice adhesion is the utilization of a superhydrophobic surface because of the extreme water-repellent property $[20,21]$. Numerous studies have been undertaken to explore the anti-icing property of superhydrophobic surface [22-24]. It is reported that a superhydrophobic surface with hierarchical micro/nanostructures can reduce ice adhesion and delay ice formation by decreasing contact angle hysteresis and reducing the contact area between droplet and surface [25-29]. For example, the low adhesion was measured on the superhydrophobic surface under supersaturated conditions due to the presence of stable air pockets compared to the smooth surface [30]. A hierarchical-structured superhydrophobic surface showed a robust anti-icing performance at $-10{ }^{\circ} \mathrm{C}$ because the impacting droplet can detach from the surface without adhering to the surface [31]. It should be mentioned that superhydrophobic surfaces are not always effective for anti-icing due to the presence of their limitations, such as low abrasive resistance, mechanical instability during de-icing and large ice adhesion strength under humid conditions [32]. Nevertheless, the surface stiffness is found to enhance superhydrophobicity and reduce ice adhesion under dynamic condition $[33,34]$. The contact time and heat conduction between the droplet and surface can be reduced when the droplet impacting the elastic membrane at room temperature [35-37].

In this study, we fabricate the elastic superhydrophobic surface by a combined spin-coating and laser ablation technique. The droplet impact on the cold elastic superhydrophobic membrane is systematically investigated. The effect of impacting speed and surface stiffness on the droplet impacting process are quantitatively studied through droplet maximum spreading diameter and contact time between droplet and surface. Furthermore, the ice adhesion on the cold elastic superhydrophobic membrane is compared with that on the cold elastic hydrophobic membrane. We believe that the droplet impact on the cold elastic superhydrophobic membrane can provide a new view for reducing ice adhesion and enhancing anti-icing performance in the industrial application.

\section{Materials and Methods}

\subsection{Materials}

Polydimethylsiloxane (PDMS) prepolymer (Sylgard 184) and curing agent were purchased from Dow Corning. Poly(methyl methacrylate) (PMMA) was provided from a local store.

\subsection{Fabrication of PDMS Elastic Superhydrophobic Membrane}

As shown in Figure 1, the PDMS prepolymer and curing agent were mixed in a weight ratio of 30:1, and degassed in a vacuum chamber for $1 \mathrm{~h}$. The PDMS solution was then rotated on a PMMA substrate by spin-coating to get a thin layer of PDMS solution. After curing at $80^{\circ} \mathrm{C}$ for $4 \mathrm{~h}$, the PDMS elastic membrane was carefully peeled off the PMMA substrate. The thickness of the PDMS elastic membrane can be controlled by the time and speed of the spin coating. Finally, the laser raster-scanning process was employed to gently ablate the superficial layer of the PDMS membrane at a laser power of $20 \mathrm{~W}$, speed of $2.54 \mathrm{~m} / \mathrm{s}$, and frequency of $30 \mathrm{kHz}$ in order to render the membrane surface superhydrophobic. In this work, two PDMS elastic membranes with thickness $h$ of $\sim 0.5 \mathrm{~mm}$ and $\sim 1 \mathrm{~mm}$ were fabricated.

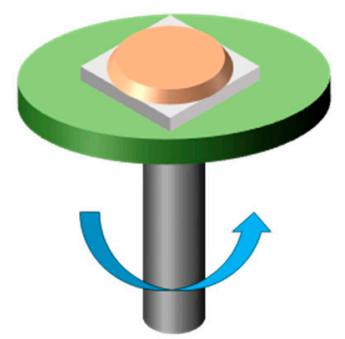

Spin-coating elastic membrane

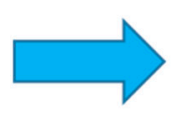

Surface modification by laser scanning

Figure 1. Fabrication of Polydimethylsiloxane (PDMS) elastic superhydrophobic membrane. 


\subsection{Characterization}

The morphologies of the PDMS elastic membrane were observed by S-4800 field emission scanning electron microscope (S-4800 II FESEM, Hitachi High-Technologies Corporation, Tokyo, Japan) with a high vacuum mode and an accelerating voltage of $15 \mathrm{kV}$. The static water contact angles and contact angle hysteresis were measured with a Ramé-Hart goniometer (model 290-U1, Succasunna, NJ, USA). Droplets of $\sim 10 \mu \mathrm{L}$ volume were gently deposited on the samples, the static contact angles were measured using the goniometer optics. To ensure repeatability of the results, all experiments were repeated three times at different locations on each sample. The value of contact angle hysteresis was calculated by measuring the advancing angle $\left(\theta_{\text {adv }}\right)$ and receding angle $\left(\theta_{\text {rec }}\right)$ via adding and removing liquid from a droplet deposited on the surface. The difference between the advancing angle and the receding angle was defined as the value of contact angle hysteresis.

\subsection{Experimental Setup for Droplet Impacting on the Cold Elastic Superhydrophobic Membrane}

The experimental platform (Figure 2) consists of a cooling system, a high-speed image acquisition system and a data acquisition system. The cooling system includes a DC regulated power supply, a cooling stage (IC20 C-P, Cole-Parmer Instrument Company, Vernon Hills, IL, USA) and a semiconductor cooler (XH-C1206, SINHEA ELECTRON, Suqian, China). The sample $(l \times w=16 \mathrm{~mm}$ $\times 8 \mathrm{~mm}$ ) sealed inside a PMMA chamber was supported by fixing both ends on the mountings and placed on the cold side of the semiconductor cooler. For comparison purposes, the droplet impact process was conducted on the rigid and elastic samples; the rigid surface was simulated by placing a glass slide under the cold elastic superhydrophobic membrane surface. The temperature of the semiconductor cooler was controlled by the DC regulated power supply, maintaining at $-30{ }^{\circ} \mathrm{C}$ on the cold side. To guarantee the normal operation of the semiconductor cooler, the heat generated by the thermal side was taken away by the cooling stage, which was kept at $-10^{\circ} \mathrm{C}$. The temperature of the sample measured by a thermocouple temperature meter (AS887, SMART SENSOR, Dongguan, China) was kept at $-5^{\circ} \mathrm{C}$ in the experiment. The relative humidity of the sealed chamber recorded by a humidity sensor (Testo 605 i, Thermo-Hygrometer Smart Probe, Titisee-Neustadt, Germany) was maintained at $5 \%$ by constantly filling in dry nitrogen, in order to avoid condensation and frost formation. The droplet with a diameter $d$ of $\sim 2.9 \mathrm{~mm}$ forming at the tip of a steel needle from a syringe pump was impacted on the center of the sample due to the gravitational force. To vary the impacting speed, the release height of the droplet was changed by adjusting the distance between the needle and the sample. The droplet impacting speed $v$ ranges from $0.1 \mathrm{~m} / \mathrm{s}$ to $1.8 \mathrm{~m} / \mathrm{s}$ in the experiment, corresponding to weber number $W e=0.4 \sim 129\left(W e=\frac{\rho v^{2} d}{\gamma}\right)$, where $\rho$ is the liquid density and $\gamma$ is the surface tension. The droplet maximum spreading diameter was measured based on the spreading diameter in the horizontal direction. The dynamic process of the droplet impingement was captured by a high-speed camera (Phantom v1212, Vision Research, Wayne, NJ, USA) at 10,000 fps from the side view.

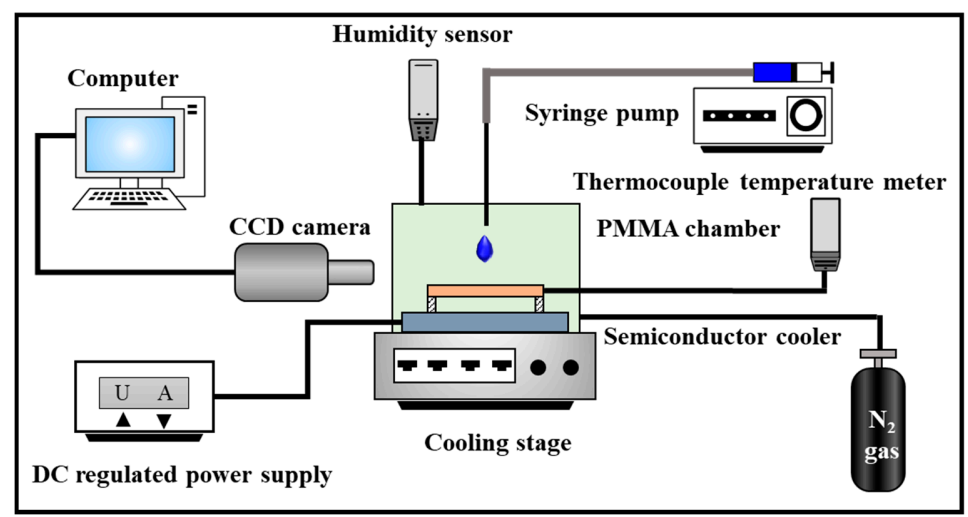

Figure 2. Experimental setup of droplet impacting on the cold elastic superhydrophobic membrane. 


\section{Results}

\subsection{Characterization of the Elastic Superhydrophobic Membrane}

Figure 3 shows the scanning electron microscopy (SEM) images of the PDMS elastic membranes before and after laser ablation. The pristine membrane surface is almost smooth without rough structures (Figure 3a), while after laser ablation, the surface is covered with microparticles, which imparts the elastic membrane surface superhydrophobic. The static water contact angle on the membranes increased from $120^{\circ}$ to $160^{\circ}$ after laser ablation, as can be seen in Figure 4 . The contact angle hysteresis of the sample decreased from $\sim 55^{\circ}$ to $\sim 2^{\circ}$ after surface modification.
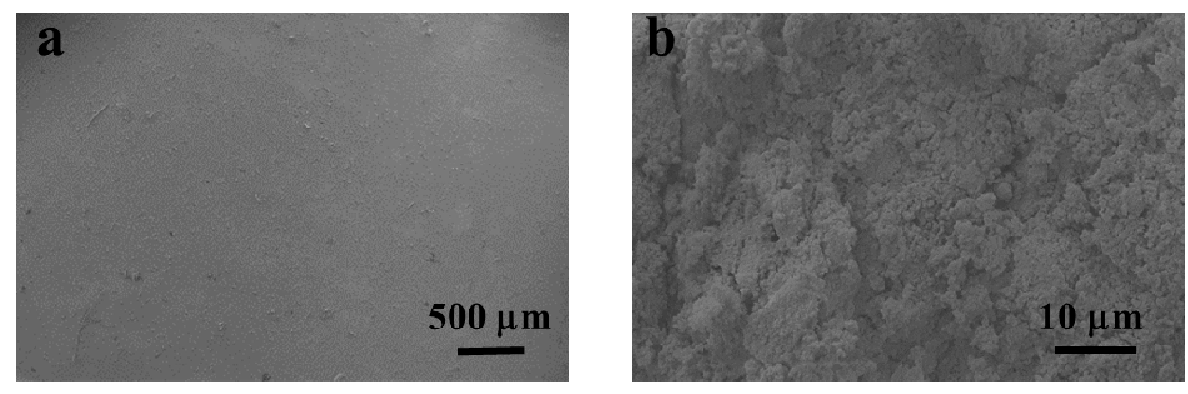

Figure 3. SEM images of the elastic membranes (a) before and (b) after laser ablation.

$\mathbf{a}$

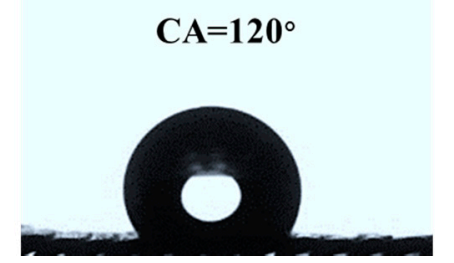

b

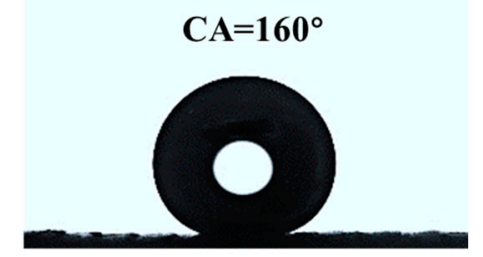

Figure 4. Static water contact angle on the elastic membranes (a) before and (b) after laser ablation.

\subsection{Dynamic Process of Droplet Impacting Cold Elastic Superhydrophobic Membranes with Varied Stiffness}

The image sequences of the droplet impacting the cold rigid and elastic superhydrophobic membrane surfaces with different stiffness $\left(-5^{\circ} \mathrm{C}\right)$ at a speed of $1.5 \mathrm{~m} / \mathrm{s}$ (corresponding to $\left.W e=90\right)$ are illustrated in Figure 5. The stiffness $k$ is calculated by $k=\frac{48 E I}{l^{3}}$, where $E$ is the elastic modulus $(E \approx 0.67 \mathrm{MPa})$ and $I\left(I=\frac{w h^{3}}{12}\right)$ is the area moment of inertia. The stiffness of the elastic superhydrophobic membranes with thickness $h$ of $\sim 0.5 \mathrm{~mm}$ and $\sim 1 \mathrm{~mm}$ are 0.65 and $5.21 \mathrm{~N} / \mathrm{m}$, respectively. As can be seen from Figure 5, the dynamic process of the droplet impacting the cold superhydrophobic membrane with varied stiffness can be divided into three periods: spreading, retracting and rebounding. Once contacting the cold superhydrophobic surface, the droplet first spreads laterally, and the kinetic energy is converted to the surface energy, reaching the maximum diameter $d_{\max }$.

On the cold rigid superhydrophobic surface (Figure 5a, Supplementary Video S1), the droplet then continues to retract, becoming elongated in the vertical direction and detaching from the surface at 19.9 ms. However, there is a little residue left on the surface when the droplet detaches, which might be ascribed to the increased adhesion force between the droplet and the cold surface, thus the kinetic energy is somewhat dissipated by the work of adhesion. The remaining droplet pins on the surface and freezes into ice eventually. 


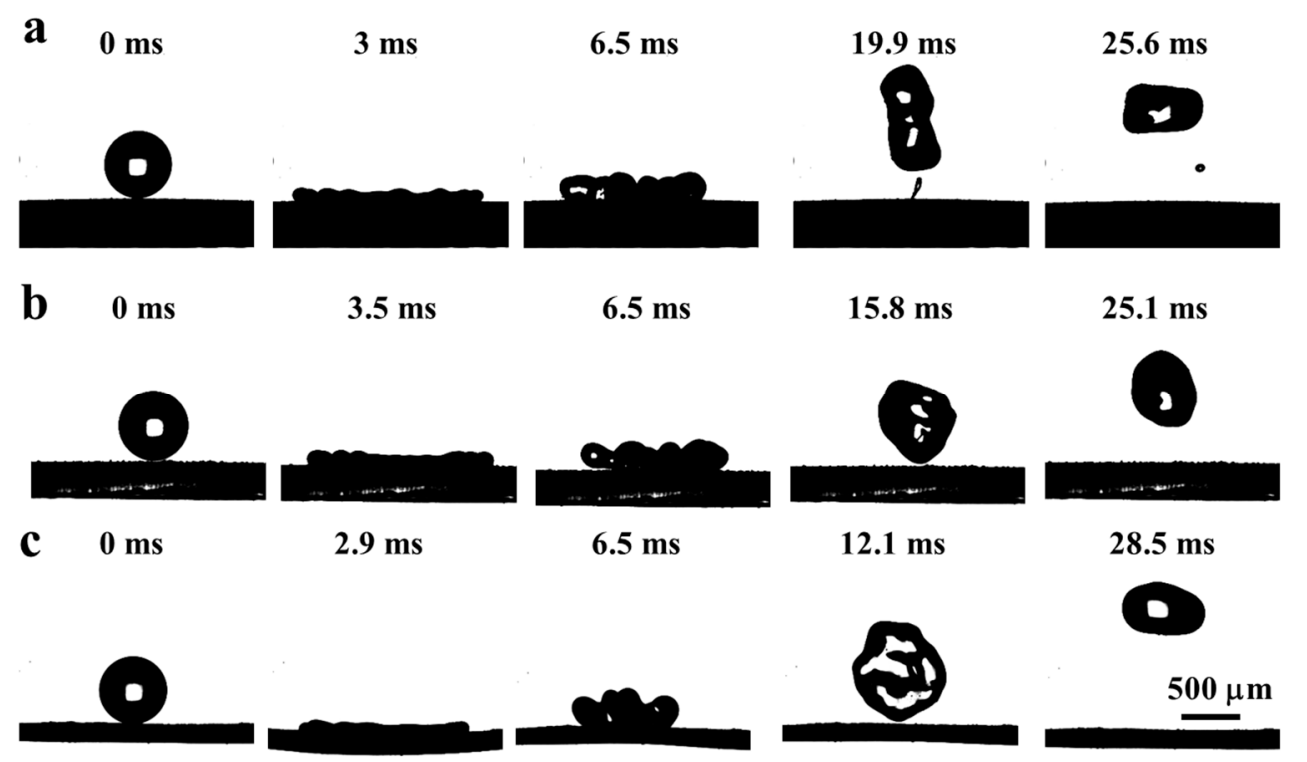

Figure 5. Droplet impacting the cold (a) rigid superhydrophobic surface and $(\mathbf{b}, \mathbf{c})$ elastic superhydrophobic membranes with stiffness $k=5.21 \mathrm{~N} / \mathrm{m}$ and $k=0.65 \mathrm{~N} / \mathrm{m}$ at a speed of $1.5 \mathrm{~m} / \mathrm{s}$.

On the cold elastic superhydrophobic membrane (Figure 5b, Supplementary Video S2), it can be seen that the membranes can be deformed once the droplet impacting the surface at the same speed of $1.5 \mathrm{~m} / \mathrm{s}$. During the droplet spreading period, the kinetic energy is converted to the surface energy of the droplet and elastic potential energy of the membrane. Thus, the droplet surface energy is smaller compared to that on the cold rigid superhydrophobic surface, resulting in a smaller droplet spreading diameter. The maximum deformation of the elastic superhydrophobic membrane occurs when the droplet reaches the maximum spreading diameter $d_{\max }$ at $3.5 \mathrm{~ms}$. During the droplet retracting period, the deformation of the elastic membrane gradually reduces and the membrane continues to move upward, exerting an elastic force on the droplet. The decreased spreading diameter of the droplet reduces the heat transfer between the droplet and the cold surface, further reducing the adhesion force between the droplet and surface, thus, the superhydrophobicity of the membrane surface is maintained, and the possibility of the droplet adhering on the cold elastic membrane is decreased. Therefore, the droplet detaches from the membrane with stiffness $k=5.21 \mathrm{~N} / \mathrm{m}$ earlier than that on the cold rigid surface. As shown in Figure $5 b$, the entire droplet can be totally detached from the cold elastic membrane surface (stiffness $k=5.21 \mathrm{~N} / \mathrm{m}$ ) with no droplet residual left on the surface.

The extent of the membrane deformation is not only up to the droplet impacting speed but also related to the stiffness $k$ of the membrane. As can be seen in Figure $5 c$, when the droplet impacts on the cold elastic membrane with a lower stiffness $(k=0.65 \mathrm{~N} / \mathrm{m}$ ) at the same speed of $1.5 \mathrm{~m} / \mathrm{s}$ (Supplementary Video S3), the superior surface elasticity causes a severe membrane deformation, leading to the increment of elasticity energy provided by the kinetic energy of the impacting droplet. Hence, smaller kinetic energy is converted to the surface energy, and the droplet maximum spreading diameter is smaller compared to the case when the droplet impacted the cold elastic membrane with stiffness $k=5.21 \mathrm{~N} / \mathrm{m}$. After reaching the maximum spreading, the droplet then retracts accompanied by the upward movement of the elastic membrane. The elastic force of the membrane causes the droplet to detach from the surface before full retraction. The contact time of the droplet on the surface $t_{c}=12.1 \mathrm{~ms}$ is 39\% shorter than that on the cold rigid superhydrophobic surface. It should be emphasized that the entire droplet can be completely detached from the cold elastic membrane without leaving the droplet residual and thus no ice was formed on the surface.

The visualization results reported herein demonstrate that the surface stiffness has a strong influence on the droplet spreading diameter and adhesion force between the droplet and the cold surface, which would further affect the droplet contact time and whether the droplet residual is left on 
the surface after droplet rebounding, all of which validate the low adhesion force of the cold elastic superhydrophobic membrane. In order to quantitatively analyze the dynamic process of droplet impact on the cold superhydrophobic membrane with varied stiffness, we calculate the ratio of droplet maximum spreading diameter $d_{\max }$ to initial droplet diameter $d$ on various surfaces. As shown in Figure 6, the surface stiffness has a significant influence on the spreading ratio, which increases (from 2.5 to 2.7 ) with the increase of membrane stiffness (from 0.65 to $5.21 \mathrm{~N} / \mathrm{m}$ ). The droplet has the largest spreading ratio when the droplet impacts on the cold rigid superhydrophobic surface.

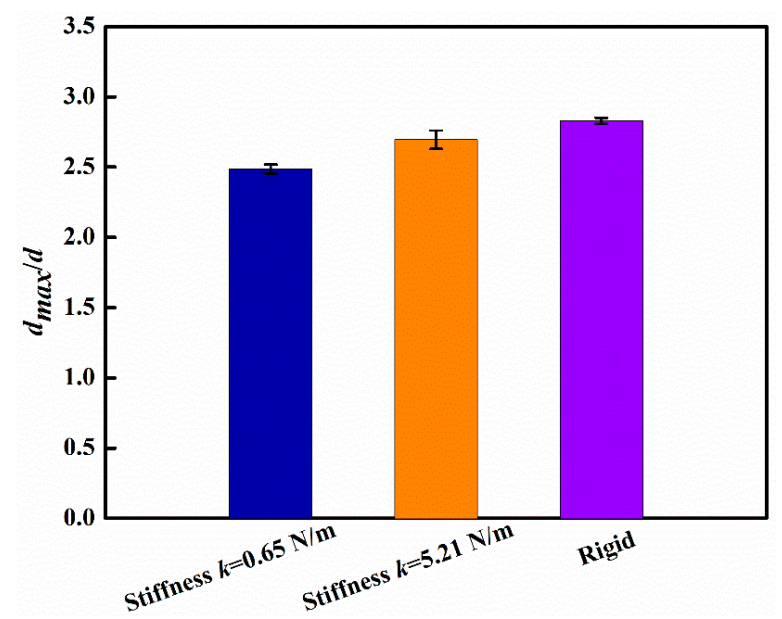

Figure 6. The ratio of droplet maximum spreading diameter to initial droplet diameter on the membrane surfaces with different stiffness.

\subsection{Effect of Droplet Impacting Speed on the Cold Elastic Superhydrophobic Membrane}

In addition to the surface stiffness, the impacting speed is also a key factor that influences the rebounding behavior of the droplet. Figure 7 presents the droplet impacting the cold elastic superhydrophobic membrane surface with a stiffness $k \sim 0.65 \mathrm{~N} / \mathrm{m}$ at different impacting speeds. As shown in Figure $7 \mathrm{a}$, when the droplet impacts the cold elastic membrane surface at a speed of $0.6 \mathrm{~m} / \mathrm{s}(W e \sim 14)$, the droplet first reaches the maximum spreading diameter $d_{\max }$ at $4.2 \mathrm{~ms}$ and detaches from the surface with an elongated shape at $15.5 \mathrm{~ms}$. At a higher impacting speed of $0.9 \mathrm{~m} / \mathrm{s}(W e \sim 32)$, the deformation degree of the elastic membrane increases, resulting in the droplet to rebound from the surface before fully undergoing surface energy to kinetic energy conversion (Figure 7b). Meanwhile, during the droplet retracting period, the elastic energy is also transformed into droplet kinetic energy, thus the droplet detaches from the surface with an irregular shape at $13.4 \mathrm{~ms}$, which is shorter than the time when droplet impacting the surface at the speed of $0.6 \mathrm{~m} / \mathrm{s}$.

A further increase in the droplet impacting speed to $1.8 \mathrm{~m} / \mathrm{s}(W e \sim 129)$ significantly increases the droplet maximum spreading diameter. The increased droplet spreading diameter facilitates the heat transfer between the droplet and the cold elastic membrane surface during the impacting process, which would increase the possibility of droplet adhering on the surface. Moreover, the elastic energy of the membrane is also increased at the higher impacting speed, resulting in an increase of the deformation degree of the elastic membrane. Consequently, the droplet is driven by a larger upward elastic force during the retracting period, leading to shorter contact time. Therefore, the droplet can rebound from the cold elastic membrane without droplet pining on the surface at the impacting speed of $1.8 \mathrm{~m} / \mathrm{s}$. 


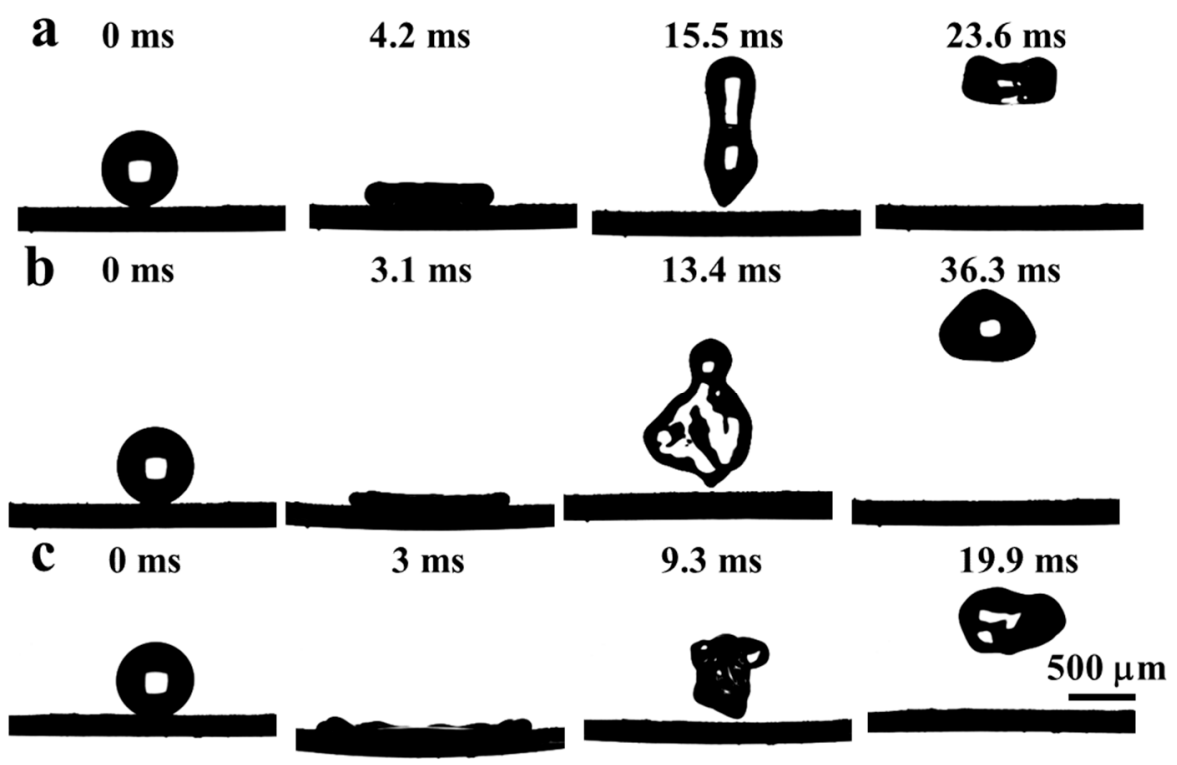

Figure 7. Droplet impacting the elastic cold superhydrophobic membrane surface with stiffness $k \sim 0.65 \mathrm{~N} / \mathrm{m}$ at impacting speed of (a) $0.6 \mathrm{~m} / \mathrm{s}$; (b) $0.9 \mathrm{~m} / \mathrm{s}$; and (c) $1.8 \mathrm{~m} / \mathrm{s}$.

Figure 8 gives the maximum spreading diameter $d_{\max }$ when the droplet impacts the cold elastic superhydrophobic membrane surface with stiffness $k \sim 0.65 \mathrm{~N} / \mathrm{m}$ at the impacting speed of $0.6 \sim 1.8 \mathrm{~m} / \mathrm{s}$. It can be seen that the maximum spreading diameter of the droplet increases from the $4.9 \mathrm{~mm}$ to $6.1 \mathrm{~mm}$ when the impacting speed increases from 0.6 to $1.2 \mathrm{~m} / \mathrm{s}$. When the impacting speed is $1.8 \mathrm{~m} / \mathrm{s}$, the maximum spreading diameter is up to $8.2 \mathrm{~mm}$, which is $40 \%$ larger than that at the speed of $0.6 \mathrm{~m} / \mathrm{s}$.

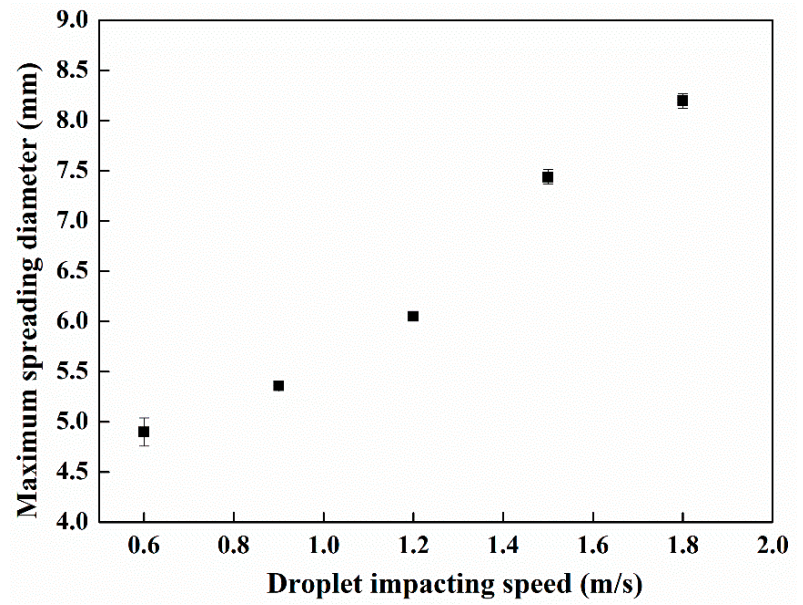

Figure 8. The maximum spreading diameter of the droplet with different impacting speed.

Figure 9 presents the contact time $t_{c}$ when the droplet impacts the cold elastic superhydrophobic membrane surface with stiffness $k \sim 0.65 \mathrm{~N} / \mathrm{m}$ at various impacting speeds. Although the surface energy is increased with the increase of the impacting speed, the elastic energy of the cold membrane is enlarged as well. A gradually increased elastic force is exerted on the droplet when the impacting speed increases from 0.6 to $1.8 \mathrm{~m} / \mathrm{s}$, so the contact time of the droplet on the cold elastic membrane is decreased (from 15.6 to $9.3 \mathrm{~ms}$ ). It should be emphasized that the droplet can completely detach from the cold elastic superhydrophobic membrane surface with stiffness $k \sim 0.65 \mathrm{~N} / \mathrm{m}$ even when the impacting speed reaches to $1.8 \mathrm{~m} / \mathrm{s}$, indicating that the adhesion force between the droplet and the cold surface is very low owing to the surface elasticity and superhydrophobicity. 


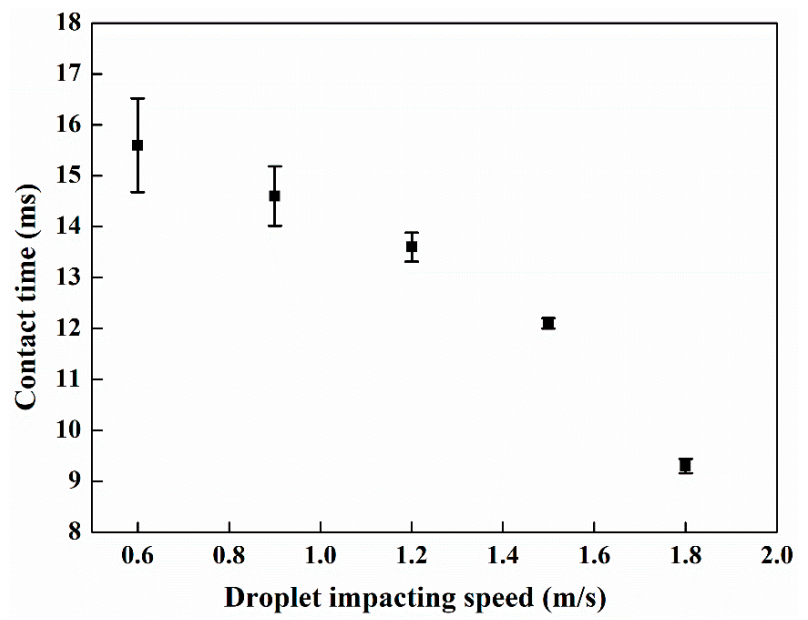

Figure 9. The contact time of droplet on the cold elastic membrane surfaces at different impacting speed.

\subsection{Dynamic Process of Droplet Impacting on the Cold Elastic Hydrophobic Membrane}

The influence of surface wettability on the droplet impacting the cold elastic hydrophobic membrane is also investigated. The static contact angle of the elastic membrane is $120^{\circ}$ without laser ablation (Figure 4a). Figure 10a shows the droplet impact on the horizontal cold elastic hydrophobic membrane surface with stiffness $k \sim 0.65 \mathrm{~N} / \mathrm{m}$ at the impacting speed of $0.6 \mathrm{~m} / \mathrm{s}$. When the droplet impacts the cold elastic hydrophobic membrane, the droplet spreading time is increased due to the relatively wettable surface. The droplet reaches the maximum spreading diameter at $4.8 \mathrm{~ms}$, which is longer than that of the droplet impacting the cold elastic superhydrophobic membrane at the same speed (Figure 10a). The extended spreading process of the droplet increases the heat transfer between the droplet and the cold membrane, leading to the increased adhesion force. During the droplet retracting period, it is difficult for the droplet to recover and rebound because the droplet base that contacted with the cold membrane could have frozen into ice. The droplet sticks on the cold elastic hydrophobic membrane eventually (19.6 ms).

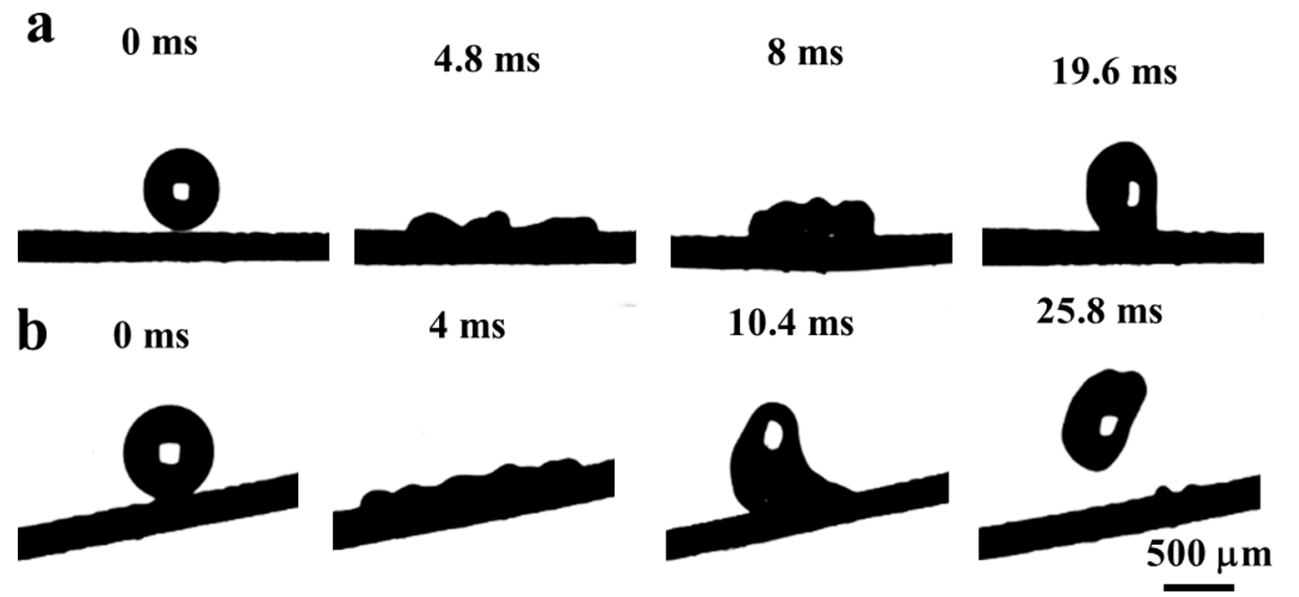

Figure 10. Droplet impacting on the (a) horizontal and (b) inclined time of droplet elastic cold hydrophobic membrane surface at $10^{\circ}$ titled angle with $0.6 \mathrm{~m} / \mathrm{s}$ impacting speed.

We also studied the droplet impact process on the inclined cold elastic hydrophobic membrane surface (tilted $10^{\circ}$ from the horizontal direction) with the impacting speed of $0.6 \mathrm{~m} / \mathrm{s}$. As shown in Figure 10b, the droplet reaches the maximum spreading diameter at $4 \mathrm{~ms}$; however, during the droplet retracting period, the droplet is driven by the elastic force and component force of gravity along the inclined cold elastic membrane surface, and is hindered by the adhesion force. Thus, the droplet retracts while moving downwards along the inclined cold elastic hydrophobic membrane, and detaches 
from the inclined cold elastic hydrophobic membrane with a little part of the droplet pinning on the surface $(25.8 \mathrm{~ms})$. This may be due to the large contact angle hysteresis of the hydrophobic surface $\left(\sim 55^{\circ}\right)$ compared to the superhydrophobic surfaces $\left(\sim 2^{\circ}\right)$ results in a large adhesion between the droplet and the surface, suggesting that contact angle hysteresis is an important factor for icephobicity.

\section{Conclusions}

In conclusion, two kinds of elastic membranes with different stiffness $(k=5.21 \mathrm{~N} / \mathrm{m}$ and $k=0.65 \mathrm{~N} / \mathrm{m})$ were prepared by a spin coating and laser ablation technique. The dynamic behaviors of droplets impacting the cold elastic superhydrophobic membrane were systematically investigated. The influence of surface stiffness and impacting speed was quantitatively analyzed to validate the low ice adhesion on the cold elastic superhydrophobic membrane. The conclusions can be summarized as:

- Differing from the cold rigid superhydrophobic surface, the droplet impacting the cold elastic superhydrophobic membrane can be detached from the cold surface completely without pinning on the surface at different impacting speeds ranging from $0.6 \mathrm{~m} / \mathrm{s}$ to $1.8 \mathrm{~m} / \mathrm{s}$, exhibiting the low ice adhesion force on the elastic superhydrophobic membrane surfaces.

- The lower the surface stiffness corresponds to the larger deformation degree of the elastic membrane and to the smaller maximum droplet spreading diameter. Moreover, the contact time decreases with the increase of the impacting speed as for the same stiffness of the cold elastic superhydrophobic membrane.

- The droplet impacting the cold elastic hydrophobic membrane cannot totally detach from the surface even at low impacting speed because the extended spreading time accelerates the heat transfer, increasing the adhesion force between the droplet and the cold elastic membrane underneath.

Supplementary Materials: The following are available online at http://www.mdpi.com/2079-6412/10/10/964/s1, Video S1: Droplet impacting on the cold rigid superhydrophobic surface at a speed of $1.5 \mathrm{~m} / \mathrm{s}$ is shown; Video S2: Droplet impacting on the cold elastic superhydrophobic membrane at a speed of $1.5 \mathrm{~m} / \mathrm{s}$ is shown (Stiffness $k=5.21 \mathrm{~N} / \mathrm{m}$ ); Droplet impacting on the cold elastic superhydrophobic membrane at a speed of $1.5 \mathrm{~m} / \mathrm{s}$ is shown (Stiffness $k=0.65 \mathrm{~N} / \mathrm{m}$ ).

Author Contributions: Conceptualization, X.C.; methodology, X.C. and C.Q.; validation, C.Q.; formal analysis, C.Q. and X.C.; writing-original draft preparation, C.Q. and X.C.; writing-review and editing, X.C. and Q.L.; supervision, X.C. and Q.L.; project administration, X.C. and Q.L. All authors have read and agreed to the published version of the manuscript.

Funding: This research was funded by National Key R\&D Program of China (2018YFA0209500), National Natural Science Foundation of China (51706100), Natural Science Foundation of Jiangsu Province (BK20180477), and Fundamental Research Funds for the Central Universities (30918011205).

Conflicts of Interest: The authors declare no conflict of interest.

\section{References}

1. Li, Y.; Jin, J.; Chen, T.; Han, L.; Cong, Q. Effect of an elastic surface on snow and ice accumulation on vehicles. Cold Reg. Sci. Technol. 2020, 180, 103154. [CrossRef]

2. Liu, Y.; Li, X.; Jin, J.; Liu, J.; Yan, Y.; Han, Z.; Ren, L. Anti-icing property of bio-inspired micro-structure superhydrophobic surfaces and heat transfer model. Appl. Surf. Sci. 2017, 400, 498-505. [CrossRef]

3. Shen, Y.; Wu, Y.; Tao, J.; Zhu, C.; Chen, H.; Wu, Z.; Xie, Y. Spraying fabrication of durable and transparent coatings for anti-icing application: Dynamic water repellency, icing delay, and ice adhesion. ACS Appl. Mater. Interfaces 2018, 11, 3590-3598. [CrossRef] [PubMed]

4. Yirtici, O.; Ozgen, S.; Tuncer, I.H. Predictions of ice formations on wind turbine blades and power production losses due to icing. Wind. Energy 2019, 22, 945-958. [CrossRef]

5. Gao, L.; Liu, Y.; Hu, H. An experimental investigation of dynamic ice accretion process on a wind turbine airfoil model considering various icing conditions. Int. J. Heat Mass Transf. 2019, 133, 930-939. [CrossRef]

6. Zhao, Z.; Chen, H.; Liu, X.; Liu, H.; Zhang, D. Development of high-efficient synthetic electric heating coating for anti-icing/de-icing. Surf. Coat. Technol. 2018, 349, 340-346. [CrossRef] 
7. Meng, X.; Hu, H.; Li, C.; Abbasi, A.; Cai, J.; Hu, H. Mechanism study of coupled aerodynamic and thermal effects using plasma actuation for anti-icing. Phys. Fluids 2019, 31, 037103. [CrossRef]

8. Li, D.; Chen, Z. Experimental study on instantaneously shedding frozen water droplets from cold vertical surface by ultrasonic vibration. Exp. Therm. Fluid Sci. 2014, 53, 17-25. [CrossRef]

9. Jung, S.; Dorrestijn, M.; Raps, D.; Das, A.; Megaridis, C.M.; Poulikakos, D. Are superhydrophobic surfaces best for icephobicity? Langmuir 2011, 27, 3059-3066. [CrossRef]

10. Kreder, M.J.; Alvarenga, J.; Kim, P.; Aizenberg, J. Design of anti-icing surfaces: Smooth, textured or slippery? Nat. Rev. Mater. 2016, 1, 15003. [CrossRef]

11. Ng, Y.-H.; Tay, S.-W.; Hong, L. Formation of Icephobic Surface with micron-scaled hydrophobic heterogeneity on polyurethane aerospace coating. Acs Appl. Mater. Interfaces 2018, 10, 37517-37528. [CrossRef] [PubMed]

12. Chen, J.; Dou, R.; Cui, D.; Zhang, Q.; Zhang, Y.; Xu, F.; Zhou, X.; Wang, J.; Song, Y.; Jiang, L. Robust prototypical anti-icing coatings with a self-lubricating liquid water layer between ice and substrate. Acs Appl. Mater. Interfaces 2013, 5, 4026-4030. [CrossRef]

13. Golovin, K.; Kobaku, S.P.R.; Lee, D.H.; DiLoreto, E.T.; Mabry, J.M.; Tuteja, A. Designing durable icephobic surfaces. Sci. Adv. 2016, 2, e1501496. [CrossRef] [PubMed]

14. Lai, Y.; Huang, J.; Cui, Z.; Ge, M.; Zhang, K.; Chen, Z.; Chi, L. Recent advances in $\mathrm{TiO}_{2}$-based nanostructured surfaces with controllable wettability and adhesion. Small 2015, 12, 2203-2224. [CrossRef] [PubMed]

15. Subramanyam, S.P.B.; Rykaczewski, K.; Varanasi, K.K. Ice adhesion on lubricant-impregnated textured surfaces. Langmuir 2013, 29, 13414-13418. [CrossRef] [PubMed]

16. Dou, R.; Chen, J.; Zhang, Y.; Wang, X.; Cui, D.; Song, Y.; Jiang, L.; Wang, J. Anti-icing coating with an aqueous lubricating layer. ACS Appl. Mater. Interfaces 2014, 6, 6998-7003. [CrossRef] [PubMed]

17. Chu, F.; Wu, X.; Wang, L. Dynamic melting of freezing droplets on ultraslippery superhydrophobic surfaces. ACS Appl. Mater. Interfaces 2017, 9, 8420-8425. [CrossRef]

18. Liu, Q.; Yang, Y.; Huang, M.; Zhou, Y.; Liu, Y.; Liang, X. Durability of a lubricant-infused Electrospray Silicon Rubber surface as an anti-icing coating. Appl. Surf. Sci. 2015, 346, 68-76. [CrossRef]

19. Long, Y.; Yin, X.; Mu, P.; Wang, Q.; Hu, J.; Li, J. Slippery liquid-infused porous surface (SLIPS) with superior liquid repellency, anti-corrosion, anti-icing and intensified durability for protecting substrates. Chem. Eng. J. 2020, 401, 126137. [CrossRef]

20. Liu, Y.; Moevius, L.; Xu, X.; Qian, T.; Yeomans, J.M.; Wang, Z. Pancake bouncing on superhydrophobic surfaces. Nat. Phys. 2014, 10, 515-519. [CrossRef]

21. Chen, X.; Ma, R.; Zhou, H.; Zhou, X.; Che, L.; Yao, S.; Wang, Z. Activating the microscale edge effect in a hierarchical surface for frosting suppression and defrosting promotion. Sci. Rep. 2013, 3, 2515. [CrossRef] [PubMed]

22. Cao, L.; Jones, A.K.; Sikka, V.K.; Wu, J.; Gao, D. Anti-icing superhydrophobic coatings. Langmuir 2009, 25, 12444-12448. [CrossRef] [PubMed]

23. Emelyanenko, A.M.; Boinovich, L.B.; Bezdomnikov, A.A.; Chulkova, E.V.; Emelyanenko, K.A. Reinforced superhydrophobic coating on silicone rubber for longstanding anti-icing performance in severe conditions. ACS Appl. Mater. Interfaces 2017, 9, 24210-24219. [CrossRef] [PubMed]

24. Pan, S.; Wang, N.; Xiong, D.; Deng, Y.; Shi, Y. Fabrication of superhydrophobic coating via spraying method and its applications in anti-icing and anti-corrosion. Appl. Surf. Sci. 2016, 389, 547-553. [CrossRef]

25. Javan-Mashmool, M.; Volat, C.; Farzaneh, M. A new method for measuring ice adhesion strength at an ice-substrate interface. Hydrol. Process. 2006, 20, 645-655. [CrossRef]

26. He, Y.; Jiang, C.; Cao, X.; Chen, J.; Tian, W.; Yuan, W. Reducing ice adhesion by hierarchical micro-nano-pillars. Appl. Surf. Sci. 2014, 305, 589-595. [CrossRef]

27. Maitra, T.; Giger, M.E.; Kandrical, V.; Ruesch, T.; Jung, S.; Poulikakos, D. Superhydrophobicity vs. ice adhesion: The quandary of robust icephobic surface design. Adv. Mater. Interfaces 2015, 2, 1500330. [CrossRef]

28. Ling, E.J.Y.; Uong, V.; Renault-Crispo, J.-S.; Kietzig, A.-M.; Servio, P. Reducing ice adhesion on nonsmooth metallic surfaces: Wettability and topography effects. ACS Appl. Mater. Interfaces 2016, 8, 8789-8800. [CrossRef]

29. Shen, Y.; Wang, G.; Tao, J.; Zhu, C.; Liu, S.; Jin, M.; Xie, Y.; Chen, Z. Anti-icing performance of superhydrophobic texture surfaces depending on reference environments. Adv. Mater. Interfaces 2017, 4, 1700836. [CrossRef] 
30. Subramanyam, S.P.B.; Kondrashov, V.; Rühe, J.; Varanasi, K.K. Low ice adhesion on nano-textured superhydrophobic surfaces under supersaturated conditions. ACS Appl. Mater. Interfaces 2016, 8, 12583-12587. [CrossRef]

31. Shen, Y.; Tao, J.; Wang, G.; Zhu, C.; Chen, H.; Jin, M.; Xie, Y. Bioinspired fabrication of hierarchical-structured superhydrophobic surfaces to understand droplet bouncing dynamics for enhancing water repellency. J. Phys. Chem. C 2018, 122, 7312-7320. [CrossRef]

32. Kulinich, S.A.; Farhadi, S.; Nose, K.; Du, X.W. Superhydrophobic Surfaces: Are they really ice-repellent? Langmuir 2011, 27, 25-29. [CrossRef] [PubMed]

33. Vasileiou, T.; Gerber, J.; Prautzsch, J.; Schutzius, T.M.; Poulikakos, D. Superhydrophobicity enhancement through substrate flexibility. Proc. Natl. Acad. Sci. USA 2016, 113, 13307-13312. [CrossRef] [PubMed]

34. Wang, L.; Gong, Q.; Zhan, S.; Jiang, L.; Zheng, Y. Robust anti-icing performance of a flexible superhydrophobic surface. Adv. Mater. 2016, 28, 7729-7735. [CrossRef] [PubMed]

35. Alizadeh, A.; Bahadur, V.; Shang, W.; Zhu, Y.; Buckley, D.; Dhinojwala, A.; Sohal, M. Influence of Substrate Elasticity on Droplet Impact Dynamics. Langmuir 2013, 29, 4520-4524. [CrossRef] [PubMed]

36. Weisensee, P.B.; Tian, J.; Miljkovic, N.; King, W.P. Water droplet impact on elastic superhydrophobic surfaces. Sci. Rep. 2016, 6, 30328. [CrossRef]

37. Zhang, C.; Wu, Z.; Shen, C.; Zheng, Y.; Yang, L.; Liu, Y.; Ren, L. Effects of eigen and actual frequencies of soft elastic surfaces on droplet rebound from stationary flexible feather vanes. Soft Matter 2020, 16, 5020-5031. [CrossRef]

(C) 2020 by the authors. Licensee MDPI, Basel, Switzerland. This article is an open access article distributed under the terms and conditions of the Creative Commons Attribution (CC BY) license (http://creativecommons.org/licenses/by/4.0/). 